\section{Information, communication and equitable access to health care: a conceptual note}

\author{
Informação, comunicação e acesso eqüitativo aos \\ cuidados de saúde: um comentário conceitual
}

Michael Thiede 1

Di McIntyre 1

\footnotetext{
1 School of Public Health and Family Medicine, University of Cape Town, Cape Town, South Africa.

Correspondence M. Thiede

Health Economics Unit, School of Public Health and Family Medicine, University of Cape Town.

Observatory 7925

South Africa.

mthiede@heu.uct.ac.za
}

\section{Abstract}

This conceptual paper addresses the health policy goal of equitable access to health care from a perspective that highlights the role of choice. It sketches a framework around the three access dimensions availability, affordability, and acceptability. The "degree of fit" with respect to each of these dimensions between the health system and individuals or communities plays a role in determining the level of access to health services by outlining the existing choice set. Yet it is the degree of informedness about the choices that ultimately determines access to health services. Access is therefore defined as the freedom to utilize. The paper focuses on information and its properties, which cut across the dimensions of access. It is argued that equity-oriented health policy should stimulate communicative action in order to empower individuals and communities by expanding their subjective choice sets.

Equity in Access; Health Services Acess; Health Communication

\section{Introduction}

A key focus of both health policy and health equity research rests on conceptualizing access to health care. Equitable access has become a popular policy objective and is often interpreted as equal access for equal need 1 . We should always be aware that access, like equity and many other terms in economic and social theory, is neither precisely definable so that it may satisfy people from different ideological backgrounds nor is it measurable in a definite manner, in the way that temperature or weight are measurable. Public health research is still heavily influenced by the health sciences, where unambiguous terminology and measurability are two constituents of the discipline's self-perception. Another, more recent, influence is from health economics, where measurability also often decides the fate of a concept. There is a risk of concepts being discarded when they appear to resist being approached with economic tools. The beauty and usefulness of debates in other areas of the social sciences are often not recognized. We believe that this is one reason why there has not been a continuous and passionate debate around health systems equity and access to health care.

The argument about why access may be a better basis for defining equity in health care than health services utilization was presented a long time ago 2 and has come up regularly in subsequent debates $3,4,5,6$. Improving access to health 
services ranks among the strategic health policy goals across the globe. In order to improve access equitably, the concept needs to be elucidated, if not operationalized.

The interpretation of access as the opportunity to use and therefore a precondition to utilization has been widely accepted. Opportunity can be described in an objective sense as a condition permitting a particular action. There appears to be broad agreement that health service utilization patterns may differ between individuals with equal health care needs without negative implications for equity if and only if these differences reflect individuals' sovereign choices. Yet the opportunity to use does not fully cover the notion of access. Opportunity relates to favorable circumstances or the possibility to use. However, in order to speak of access, another precondition needs to be fulfilled, which is that of being aware of the possibility to use and being empowered to choose. We therefore favor the definition of access as the freedom to use 7 . This paper builds on the notion of empowerment and regards information as the essential prerequisite for access. The argument implies that health policy needs to reorient strategies and emphasize health communication in order to address some of the root causes of inequities in health.

\section{A common framework for access}

There are observable "factors" that facilitate or impede the opportunity to use health services. These can be subsumed under different dimensions of access. Since the early 1970s researchers have engaged with different approaches to access, acknowledging that access to health care is indeed a rather complex concept with several dimensions $8,9,10,11,12,13$. While today there is general consensus that access to health services is a multi-dimensional concept 1,14 , there are different ideas around what these are. There is not just one legitimate conceptual framework focusing on the access dimensions. However, it appears necessary and opportune to harmonize the different approaches and suggest a consolidated framework. The existence of such a framework would smooth the progress of communication between researchers in public health, assist the dialogue between researchers and policymakers, and allow comparisons of access levels between different settings. This framework cannot be randomly drafted but should be based on rigorous argument. The dimensions of the framework have to cover all relevant access factors and should be mutually exclusive to the greatest extent possible. They should also appeal to common sense. Building on the literature and a refined conceptual framework, it can be argued that the factors determining access can be captured by the three dimensions availability, affordability, and acceptability ${ }^{15}$. The availability of health care captures all factors that relate to the actual existence of a specific service within reach of the client as well as aspects of user-friendliness, e.g. the existence of appointment systems and the convenience of opening hours. The distance to a facility is one of the indicators of access factors under this dimension that are easily measured. A number of recent studies address this aspect of access 16,17. Affordability refers to the direct and indirect costs of care relative to the client's ability to pay. Health care financing arrangements strongly affect the affordability dimension. Lastly, acceptability covers many of the subjective, social, and cultural factors, such as the degree to which a certain service is culturally secure 18 .

It becomes clear that the level of access to health care is determined by the "degree of fit" between individuals or communities and the health system 13 . Hence, access reflects the interplay between the "supply side" and the "demand side" in health care. It is a relative concept, as a certain level of access needs to be assessed against a base level or a benchmark.

\section{Information}

In our argument, we want to focus on information as a core element that cuts across the access dimensions. We feel that even though the element of choice has been highlighted in the literature, this element that fills the gap between the opportunity to use and actual utilization has not been appropriately discussed. We also believe that this is where a focus of the equity debate should lie, as empowering people to make choices in health care ought to be a fundamental health policy objective in a democratic society. We will explore the properties of information required to improve access to health care, which is seen to be the freedom to utilize health services ?

Information has been dealt with extensively in health economics, imperfect information and uncertainty being regarded as key attributes of the health economy 19. The economics of information have greatly contributed to the understanding of insurance markets, and the understanding of asymmetric information and agency relationships in health care markets has shaped the way in which health systems are analyzed and in which their design is improved 20. In this paper, we are not concerned with incentive ef- 
fects resulting from distributional patterns of information between the actors in health care. We rather look at the characteristics of information that impact the health system's clients' subjective choice sets and the mechanisms in which information is transferred between the actors in the health system.

Information is a term which is used in today's language in a broad range of contexts, generally without skepticism or uncertainty about its meaning. However, information is a rather poorly defined concept. Whereas according to a broad understanding of the term any signal that our senses receive and that gets processed by the human brain may be interpreted as information, we would like to limit the definition for our context to information that is transferred between humans. Etymologically, information means putting something into form or into different form, transferring form from one state to another, e.g. from the real or tangible to the ideal or abstract. Health economists regard health information and health care information as goods that are supplied and demanded within the health care system. Yet, there is hardly a good that compares with information when it comes to the importance of the degree of fit in the process of transaction. Unfortunately, research on health communication has not yet developed a full conceptual framework incorporating information effectiveness. This is a necessary step in the process of understanding how the transmission of health information impacts access to health services.

It is helpful to look back to communication research at the dawn of the information age when in their 1949 landmark publication Claude Shannon \& Warren Weaver distinguished three levels of complexity in dealing with the transfer of information 21 . The first level addresses the accuracy of the transmission of information and concentrates on the correctness of the information at the receiver end. The second and third levels refer to semantics: the second level relates to the degree to which the desired meaning is actually conveyed, the third to the degree to which the information affects behavior in the desired way - information effectiveness in the narrow sense. These three conceptual levels can guide the thinking around health communication, which again is the vehicle to empower individuals and communities to realize choices in health care and thus increase access.

The distribution of information between the actors within the health care system is extremely unequal. There are many reasons underlying the unequal distribution of information relating to health and health care, many of which are obvious, such as those defining the doctor-patient relationship, and have been discussed elsewhere. We would like to focus on the type of information that directly refers to choices relating to the utilization of health services. Information that determines whether an individual chooses to use or not to use a certain health service is an inherent element of the concept of access and relates to the dimensions of availability, affordability, and acceptability. The degree of fit between the factors subsumed under each of these dimensions from the supply side and from the demand side may appear quite good in a certain case, but still health services may not be utilized to the desired degree because of differences in information. Determinants of realized choice are the perceptions of health and illness, the subjective choice set, and individual preferences. The subjective choice set is the set of choices that relate to an individual's perception of optional actions given the information processed by the individual 7. It is often smaller than the existing or real choice set, due to a lack of awareness of options resulting from disempowerment. The fit between the supply- and demand-side factors within the three access dimensions and the amount and quality of information reflected in the subjective choice set jointly define the level of access to health services for an individual or a community. Hence the definition of access as the freedom to utilize health services, which implies that no "force" or pressure is applied and that the ultimate choice only depends on preferences.

It is thus apparent how crucial the role of information is to access to health care. The level of general informedness, which may have been achieved through education, to a significant degree determines an individual's access to social resources and thereby her social position. Indeed, informedness with respect to health and health system matters determines an individual's access to health care to a significant degree. The information that empowers people to realize a choice in the health care context is quite specific and different from the general information that is continuously all around us.

Information processing is limited by human factors. They can be presented in economic terms and include time as the key constraint. Indirect costs of information processing exist in terms of time lost for other, e.g. income-generating activities. Engaging in the processing of health information may not appear as an activity that is worthwhile pursuing. On the demand side, the normal perception of health information is that of a good to which no value can be assigned ex ante, as potential benefits of the gained knowledge refer to an uncertain scenario and depend on many other factors. Given that health itself 
is a merit good, i.e. a good that is socially desirable, it is within the responsibility of the health system to inform individuals about the potential value of specific health services. However, it can be observed that even when the health system provides health information, Shannon \& Weaver's second and third levels of information are not appropriately addressed: Health information is often neither absorbed nor comprehended by the addressee, nor can intended behavior changes or action be observed.

\section{Communication as information exchange}

The provision of health information cannot be a unidirectional process if the objective is to empower individuals or communities, expand their subjective choice sets, and thereby develop their freedom to choose. Frequently when health systems and individuals in their communities interact, the situation is characterized by a small degree of cohesion between the worldviews of the two spheres. For the conceptualization of health communication, it is helpful to adopt the concept of a lifeworld, which Habermas 22 (p. 183) defined as "the sphere of shared cultural knowledge, valid norms and accountable motivations". Communication, the exchange of information, connects lifeworlds, while it also regulates the behavior of and within social systems. Communication is social interaction and therefore plays a critical role in connecting the lifeworlds health system and community. The participation in communication increases the processing of effective information and empowers individuals or communities by enriching their subjective choice sets.

Theories of communication distinguish different levels of information effectiveness 23 . The degree to which health information becomes effective and empowers people to exercise their choice with respect to the opportunity to utilize health services depends on a broad range of determinants. Studies have demonstrated that the effectiveness of information is influenced by various characteristics on the receiver's side, such as her socioeconomic status 24 , but also the socio-cultural relation between the lifeworlds among which the interchange of information takes place 25 . Conversely, the exclusion from or the participation in communication processes is a determinant of the social position of individuals.

At a time when the health research community is dedicated to studying the social determinants of health, there is all reason to engage in the study of communication. Communication in a wider sense determines the dynamics of socio- economic and socio-cultural structures and their relation to the health system. Based on a better understanding of communicative processes and information effectiveness with a view to improved access, communication should be shaped to secure equally negotiable pathways into the health system for individuals - independent of their socioeconomic and cultural background. The outcome of interactive and participatory communication between the health system and individuals or communities will be an increase in the overlap of these lifeworlds. Interaction needs to go beyond health care as such in order to empower people to exercise choices in health care. This communicative interaction needs to address aspects of life further than the medical system. Communicative action that is characterized by an active search for mutual understanding can be initiated in the health context in a number of ways.

Rather than looking for the solution to increased access anywhere but in the medical sector - which may appear to be the implication of the framework at a first glance - there is a liability of the health system in respect to an intensified communicative engagement with individuals and communities. The framework, which distinguishes access and use by highlighting subjective choice and preference, does not imply that health managers are not challenged. The term "individual preferences" is used here in the sense of deep-seated fundamental beliefs in different healing systems and types of services and not in the sense that a person may "prefer" not to use a particular service because they do not have adequate information on the effectiveness of that service. This, again, is related to access constraints rather than what can truly be called individual preferences. The existing or real choice set needs to be extended across the three dimensions of access by increasing the "degree of fit" between the health system and the individual, and at the same time the subjective choice set needs to be extended with the help of effective information through improved communication. The framework is inherently democratic.

\section{Conclusions}

As it turns out, improving communication means improving equity. If policymakers are serious about the equity goal that postulates equal access for equal need, then they need to broaden their focus beyond the delivery of health care. A key task of health policy is to initiate and facilitate communicative processes that involve the health system on the one hand and the communities 
on the other, integrating the communities' views as a reference for the evaluation of corresponding health information. This will frequently turn out to be a difficult and unpopular task because health systems tend to develop independently of the people they are supposed to serve. Further, monitoring the success of such a primary communicative process is complex. Empowering people to choose is a task that goes hand in hand with making choices accessible. This aspect has been reprehensibly neglected in many countries. While in the context of low-and middle-income countries tradition often defines lifeworlds, tradition is the wrong mode of communication in a scenario of quickly changing lifeworlds when access to health care is at stake.

\section{Resumo}

Este artigo conceitual discute a meta política do acesso eqüitativo à assistência em saúde, com um foco especial no papel da escolha. Estabelece um arcabouço teórico baseado nas três dimensões do acesso: disponibilidade, acessibilidade financeira e aceitabilidade. No que diz respeito a cada uma dessas dimensões, o "grau de ajuste" entre o sistema de saúde e os indivíduos ou comunidades tem um papel determinante no nivel de acesso aos serviços de saúde, na medida em que define o conjunto de escolhas. No entanto, em última análise, é o grau de informação sobre as escolhas que determina o acesso aos serviços de saúde. Portanto, acesso é definido como liberdade de utilização. O artigo analisa a informação e suas características (que atravessam as diversas dimensões do acesso), argumentando que uma política de saúde eqüitativa deve estimular a ação comunicativa para fortalecer os indivíduos e as comunidades na expansão dos seus conjuntos de escolhas subjetivas.

Eqüidade no Acesso; Acesso aos Serviços, Communicação em Saúde
An increased focus on health communication can be expected to improve the socioeconomic patterns of service uptake, which in many countries and contexts are rather "regressive" in that the better-off tend to benefit more from health services than the poor. Even more importantly under a liberal worldview, the focus on health communication will improve equity in access by addressing the freedom to utilize. In order to generate effective information, health communication must be interactive and not focus on unilateral achievement but on consensus. It must also be conducive to unleashing the voices of those who tend to be most disadvantaged in the exercise of balancing need and access in health care.

\section{Contributors}

M. Thiede and D. McIntyre both contributed to the conceptualization and jointly developed the ideas reflected in the paper. M. Thiede was responsible for writing up. 


\section{References}

1. Oliver A, Mossialos E. Equity of access to health care: outlining the foundations for action. J Epidemiol Community Health 2005; 58:655-8.

2. Mooney G. Equity in health care: confronting the confusion. Eff Health Care 1983; 1:179-85.

3. Culyer A, van Doorslaer E, Wagstaff A. Access, utilisation and equity: a further comment. J Health Econ 1992; 11:207-10.

4. Culyer A, van Doorslaer E, Wagstaff A. Utilisation as a measure of equity by Mooney, Hall, Donaldson and Gerard. J Health Econ 1992; 11:93-8.

5. Mooney G, Hall J, Donaldson C, Gerard K. Utilisation as a measure of equity: weighing heat? J Health Econ 1991; 10:475-80.

6. Mooney G, Hall J, Donaldson C, Gerard K. Reweighing heat: response to Culyer, van Doorslaer and Wagstaff. J Health Econ 1992; 11:199-205.

7. Thiede M. Information and access to health care: is there a role for trust? Soc Sci Med 2005; 61: 1452-62.

8. Aday LA, Andersen R. Development of indices of access to medical care. Ann Arbor: Health Administration Press; 1975.

9. Aday LA, Andersen R. Equity of access to medical care: a conceptual and empirical overview. Med Care 1981; 19:4-27.

10. Andersen R. Revisiting the behavioural model and access to medical care: does it matter? J Health Soc Behav 1995; 36:1-10.

11. Guilliford M, Morgan M, editors. Access to health care. London: Routledge; 2003.

12. Penchansky R. The concept of access: a definition. Hyattsville: National Health Planning Information Centre, Department of Health, Education and Welfare; 1977.

13. Penchansky R, Thomas W. The concept of access: definition and relationship to consumer satisfaction. Med Care 1981; 19:127-40.

14. Gulliford M, Figueroa-Munoz J, Morgan M, Hughes D, Gibson B, Beech R, et al. What does "access to health care" mean? J Health Serv Res Policy 2002; 7:186-8.
15. McIntyre D, Thiede M. Access: unlocking the potential of health systems. Cape Town: Health Economics Unit, University of Cape Town; 2006.

16. Tanser F, Gijsbertsen B, Herbst K. Modelling and understanding primary health care accessibility and utilization in rural South Africa: an exploration using a geographical information system. Soc Sci Med 2006; 63:691-705.

17. Rosero-Bixby L. Supply and access to health services in Costa Rica 2000: a GIS-based study. Soc Sci Med 2004; 58:1271-84.

18. Wilkes E, Houston S, Mooney G. Cultural security: some cost estimates from Derbarl Yerrigan health service. New Doctor 2002; 77:13-5.

19. Arrow K. Uncertainty and the welfare economics of medical care. Am Econ Rev 1963; 53:941-73.

20. McGuire T. Physician agency. In: Culyer A, Newhouse J, editors. Handbook of health economics. v. 1A. New York: Elsevier; 2000.

21. Shannon C, Weaver W. The mathematical theory of communication. Urbana: University of Illinois Press; 1949.

22. Habermas J. Theorie des kommunikativen Handelns, Band 2: Zur Kritik der funktionalistischen Vernunft. Frankfurt: Suhrkamp Verlag; 1981.

23. Dervin B. Libraries reaching out with health information to vulnerable populations: guidance from research on information seeking and use. J Med Libr Assoc 2005; 93(4 Suppl):S74-80.

24. Akweongo P. Measuring equity in access to health care: a case study of malaria control interventions in the Kassena-Nankana district of Northern Ghana [Doctoral Dissertation]. Cape Town: Health Economics Unit, University of Cape Town; 2005.

25. Kreps GL, Kunimoto EN. Effective communication in multicultural health care settings. London: Sage Publications; 1994.

Submitted on $19 / \mathrm{Sep} / 2006$

Approved on 13/Mar/2007 